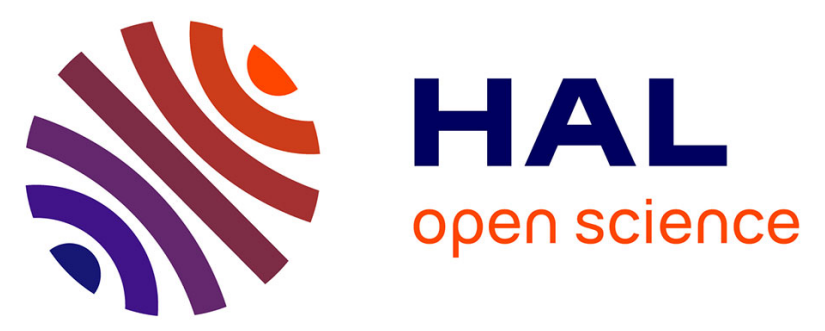

\title{
New geographical and host record of bat ectoparasite Steatonyssus (Steatonyssus) afer Radovsky and Yunker, 1963 (Mesostigmata: Gamasina: Macronyssidae)
} Maria V Orlova, Theresa M Laverty, Will K Reeves, Elena M Gratton, Mallory L Davies, Nikolay V Anisimov

\section{To cite this version:}

Maria V Orlova, Theresa M Laverty, Will K Reeves, Elena M Gratton, Mallory L Davies, et al.. New geographical and host record of bat ectoparasite Steatonyssus (Steatonyssus) afer Radovsky and Yunker, 1963 (Mesostigmata: Gamasina: Macronyssidae). Acarologia, 2020, 60 (4), pp.951-958. 10.24349/acarologia/20204411 . hal-03044240v2

\author{
HAL Id: hal-03044240 \\ https://hal.science/hal-03044240v2
}

Submitted on 16 Dec 2020

HAL is a multi-disciplinary open access archive for the deposit and dissemination of scientific research documents, whether they are published or not. The documents may come from teaching and research institutions in France or abroad, or from public or private research centers.
L'archive ouverte pluridisciplinaire HAL, est destinée au dépôt et à la diffusion de documents scientifiques de niveau recherche, publiés ou non, émanant des établissements d'enseignement et de recherche français ou étrangers, des laboratoires publics ou privés. 


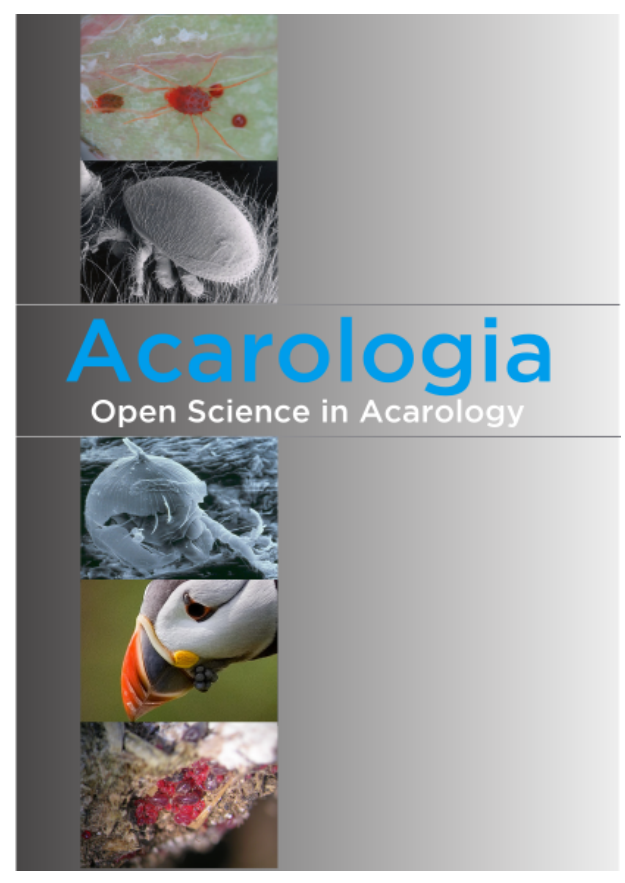

\section{Acarologia}

A quarterly journal of acarology, since 1959

Publishing on all aspects of the Acari

All information:

http://www1.montpellier.inra.fr/CBGP/acarologia/ acarologia-contact@supagro.fr

\section{OPEN ACCESS}

\section{Acarologia is proudly non-profit, with no page charges and free open access}

Please help us maintain this system by encouraging your institutes to subscribe to the print version of the journal and by sending us your high quality research on the Acari.

Subscriptions: Year 2020 (Volume 60): $450 €$ http://www1.montpellier.inra.fr/CBGP/acarologia/subscribe.php

Previous volumes (2010-2018): $250 €$ / year (4 issues)

Acarologia, CBGP, CS 30016, 34988 MONTFERRIER-sur-LEZ Cedex, France

ISSN 0044-586X (print), ISSN 2107-7207 (electronic)

The digitalization of Acarologia papers prior to 2000 was supported by Agropolis Fondation under the reference ID 1500-024 through the « Investissements d'avenir » programme

(Labex Agro: ANR-10-LABX-0001-01)
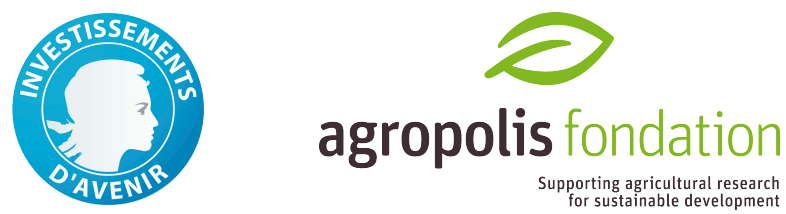

Acarologia is under free license and distributed under the terms of the

Creative Commons-BY-NC-ND which permits unrestricted non-commercial use, distribution, and reproduction in any medium, provided the original author and source are credited. 


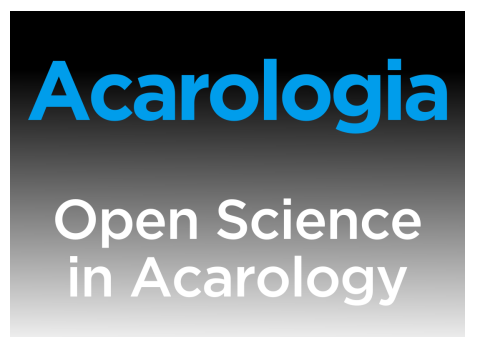

New geographical and host record of bat ectoparasite Steatonyssus (Steatonyssus) afer Radovsky and Yunker, 1963 (Mesostigmata: Gamasina: Macronyssidae)

\author{
Maria V. Orlova ${ }^{a, b}$, Theresa M. Laverty ${ }^{c}$, Will K. Reeves ${ }^{d}$, Elena M. \\ Gratton $^{c}$, Mallory L. Davies ${ }^{c}$, Nikolay V. Anisimov $^{a}$ \\ ${ }^{a}$ Tyumen State University, Tyumen, Russia. \\ ${ }^{b}$ National Research Tomsk State University, Tomsk, Russia. \\ ${ }^{c}$ Department of Fish, Wildlife, and Conservation Biology, Colorado State University, Fort Collins, \\ Colorado, USA. \\ ${ }^{d}$ Colorado State University, C. P. Gillette Museum of Arthropod Diversity, Fort Collins, Colorado, USA.
}

\section{Original research}

\section{ABSTRACT}

Steatonyssus afer is recorded for the first time from Namibia and for the first time from Cistugo seabrae (Chiroptera: Cistugidae). Our finding is the southernmost locality for $S$. afer, expanding the geographical distribution range of this ectoparasite. We give diagnostic illustrations and measurements of the species.

Keywords Steatonyssus afer; Macronyssidae; Namibia; Cistugo seabrae

\section{Introduction}

Steatonyssus is the largest genus in the family Macronyssidae and has been recorded from every major zoogeographic region (limited in the Australasian to one Australian species) (Radovsky, 1967, 2010). Radovsky (2010) recognized 53 species both in Steatonyssus (52) and Steatonysella (1) subgenera. Mites of genus Steatonyssus parasitize bats (Chiroptera: Vespertilionidae, Molossidae, Rhinolophidae, Hipposideridae, Nycteridae, Emballonuridae, and Pteropodidae), some rodents (Rodentia: Myoxidae), and elephant shrews (Macroscelidea: Macroscelididae).

According to Coffee (1973), for the Afrotropical (Ethiopian) region, 16 species belonging to the genus Steatonyssus have been recorded: Steatonyssus periblepharus Kolenati, 1858, Steatonyssus (Steatonyssus) aelleni Radovsky and Yunker, 1963; Steatonyssus (Steatonyssus) afer Radovsky and Yunker, 1963; Steatonyssus (Steatonyssus) benoiti Till and Evans, 1964; Steatonyssus (Steatonyssus) brucei Lavoipierre, 1956; Steatonyssus (Steatonyssus) calcaratus Radovsky and Yunker, 1963; Steatonyssus (Steatonyssus) crassisetosus Till and Evans, 1964; Steatonyssus (Steatonyssus) eos Zumpt and Till, 1954; Steatonyssus (Steatonyssus) hipposideros Till, 1958; Steatonyssus (Steatonyssus) mutatus Coffee, 1973; Steatonyssus (Steatonyssus) natalensis Zumpt and Patterson, 1951; Steatonyssus (Steatonyssus) nyassae Hirst, 1922; Steatonyssus (Steatonyssus) roeri Coffee, 1973; Steatonyssus (Steatonyssus) sudanensis Hirst, 1923; Steatonyssus (Steatonyssus) tibialis Till and Evans, 1964; and Steatonyssus (Steatonyssus) javensis brevisetosus Till and Evans, 1964. Most of them are known only by the first description and, in some cases, scattered records. Steatonyssus afer is known by the findings in Angola from mixed collection of hosts [(the banana pipistrelle Neoromicia nana Peters, 1852, the 


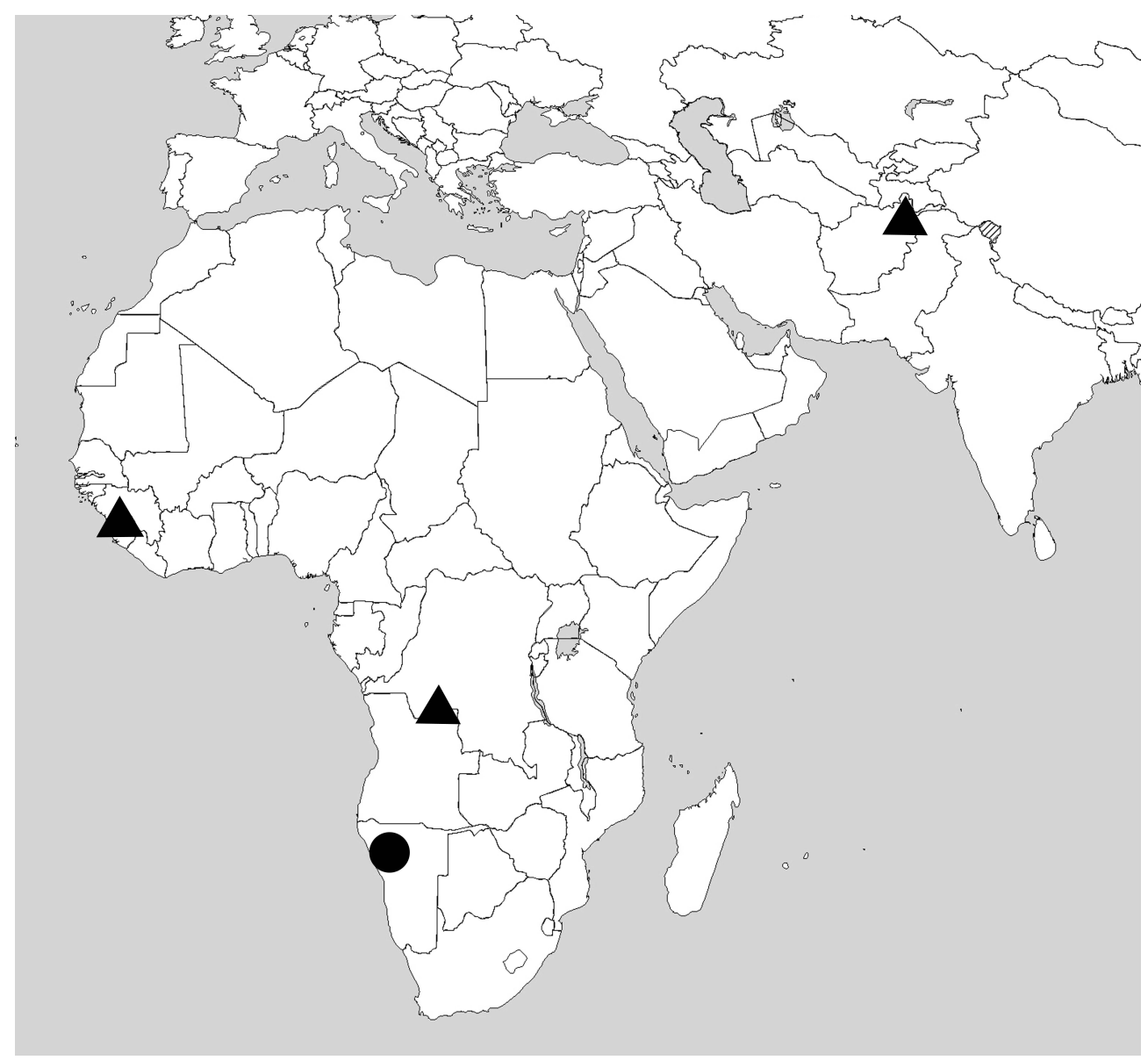

Figure 1 Map of Africa, showing previous (triangles) and new (circle) record sites for the bat ectoparasitic mite Steatonyssus (Steatonyssus) afer.

white-winged serotine Neoromicia tenuipinnis Peters, 1872 (Chiroptera: Vespertilionidae), and tha large-eared slit-faced bat Nycteris macrotis Dobson, 1876 (Chiroptera: Nycteridae)] (Radovsky and Yunker, 1963), in Sierra Leone (host was determined as a "small bat") (Till, Evans, 1964, and in Afghanistan from the serotine bat Eptesicus serotinus and the mouse-tailed bat Rhinopoma sp. (Dusbábek, 1970) (Fig. 1). Here, we report S. afer, including a brief description of adult females, in Namibia and associated with the Angolan wing-gland bat Cistugo seabrae Thomas, 1912 (Chiroptera: Cistugidae), including a brief redescription of female.

\section{Materials and methods}

We conducted research on Namib Desert bats and their ectoparasites in the Kunene Region of northwestern Namibia (Fig. 1). This region is comprised of pastoralist communal conservancies and tourism concessions bordering Skeleton Coast Park, and receives $\sim 30$ to $100 \mathrm{~mm}$ of rainfall, on average, between January and April each year (Jacobson and Jacobson, 2013).

From 6 December 2016 to 4 April 2017, we intensively examined captured bats for ectoparasites. We captured bats by deploying mist nets ( $2 \mathrm{~m}$ high by 4 to $12 \mathrm{~m}$ in length) above bodies of water for 1 to $3 \mathrm{hr}$ after sunset for a total of $120.37 \mathrm{hr}$ over 37 nights. We removed bats from mist nets within 1 to 5 min of capture and placed them in cloth bags until they could be processed 0 to 15 min later. Bats were morphologically identified using taxonomic descriptions 
by Monadjem et al. (2010) and we recorded the following data for each bat: sex, age (juvenile or adult), forearm length $(\mathrm{mm})$, body mass $(\mathrm{g})$, and reproductive status (non-reproductive, reproductive, pregnant, or lactating). The body (front, back, tail, wings, ears, uropatagium, etc.) of all bats were thoroughly and systematically surveyed in hand and examined for ectoparasites using an LED headlamp.

All ectoparasites were removed with forceps, pooled into one sample for each individual bat, and preserved in $95 \%$ ethanol before the bats were released. For each ectoparasite sample, we transferred the mites into a new vial containing 70\% ethanol and sent all mites to the Institute X-bio of Tyumen State University (Russia) for species identification. After clearing, the mites were mounted on permanent slides with Faure-Berlese's mounting medium (Whitaker, 1988). Morphological identification of mites was done by the first author (MO), according to the keys by Till and Evans (1964). The morphological terminology generally follows Evans and Till (1979). Dorsal and ventral setae were labelled according to the systems of Lindquist and Evans (1965). Photographs were taken with a digital camera AxioCam ICc5 (Zeiss, Germany) via a compound microscope AxioImager A2 (Zeiss, Germany) with a phase-contrast and DIC objectives. All measurements are given in micrometers $(\mu \mathrm{m})$.

The specimens mounted on five slides were deposited at the collection of the Tyumen State University's Museum of Zoology, Tyumen Province, Russia.

\section{Results and discussion}

Five specimens of macronyssid mites (Mesotigmata: Gamasina: Macronyssidae) were obtained from adult females of the Angolan wing-gland bat C. seabrae, in two localities of Namibia: Okongwe $\left(18^{\circ} 59^{\prime} \mathrm{S} 13^{\circ} 9^{\prime} \mathrm{E}\right)$ (one bat) and the junction of the Hoanib and Mudorib Rivers $\left(19^{\circ} 19^{\prime} \mathrm{S} 13^{\circ} 14^{\prime} \mathrm{E}\right)$ (one bat). Mites (five females) were morphologically identified as $S$. afer. Measurement information from the present study and previous ones is provided in Table 1.

\section{Family Macronyssidae}

\section{Genus Steatonyssus Kolenati, 1858}

Type species: Steatonyssus periblepharus Kolenati, 1858, by designation of Till and Evans, 1964

\section{Steatonyssus (Steatonyssus) afer Radovsky and Yunker, 1963}

\section{Figures 2-3}

Differential diagnosis (female) - Steatonyssus afer is morphologically closest to S. roeri. The anterior margin of the sternal plate can hardly be detected in S. afer (vs. well defined in $S$. roeri). In $S$. afer, the peritreme starts ventral and bends over to the dorsal surface for most of its length, while the peritrematal plate is interrupted with a leaf-like portion lying over coxae I and II ( $v s$. not interrupted plate in $S$. roeri). The setae on the opisthonotal and podonotal shields are considerably longer and thicker in $S$. afer than in $S$. roeri (54-71 vs. 40-47, respectively).

Brief description of female - Five specimens from Namibia were measured (Table 1).

Idiosoma: ovoid, light brown colour. Dorsum (Fig.2A-D), podonotal shield clearly reticulated, with 11 pairs of setae, $j 2$ present; setae $z 2-3, s 3-4$ longest; posterior margin of shield flat (Fig. 2A, C); opisthonotal shield concave anteriorly with pronounced reticulate pattern, bearing 7 setal pairs, $J 1-3$ long, S5 short, $J 5$ microseta (Figs. 2B, D). Venter, sternal shield, not sharply demarcated from reticulate presternal area, posterior region heavily sclerotized (Fig. 3), with 2 pairs of pores and 3 setal pairs. Epigynial shield triangular, anterior flap has slender sclerotized median projection. Anal shield obovate, with 3 setae. Idiosomal unsclerotized integument with about 102-110 pairs of smooth setae (64-69 on dorsal side, and 38-41 on ventral side); peritremes end over coxa III; peritrematal shield interrupted, separated anterior leaf-like part situated over coxa I (Fig. 4). 


\section{Acarologia}
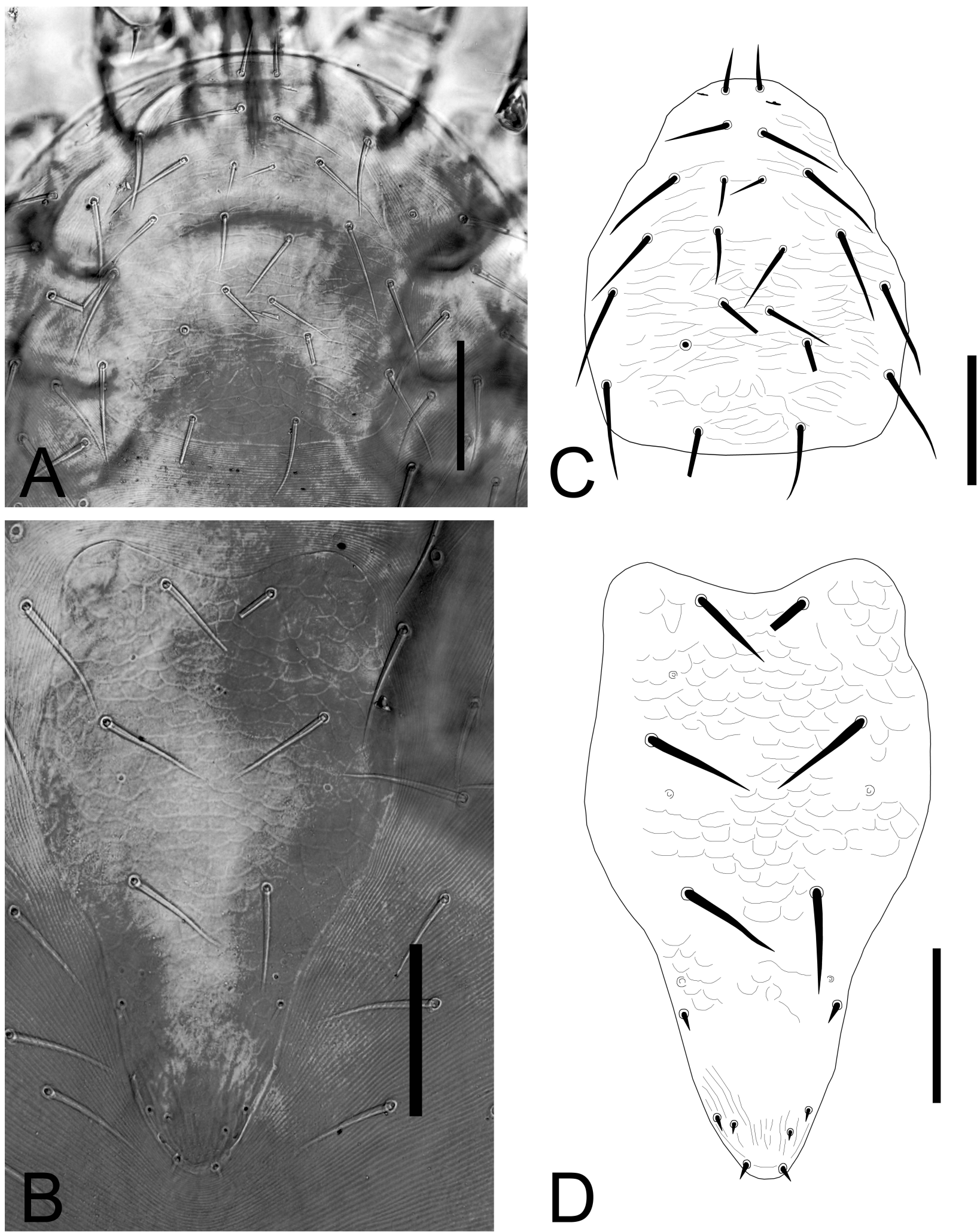

Figure 2 Female of Steatonyssus afer. A, C. Podonotal shield (scale bar $100 \mu \mathrm{m}$ ); B, D. Opisthonotal shield (scale bar $100 \mu \mathrm{m}$ ). 


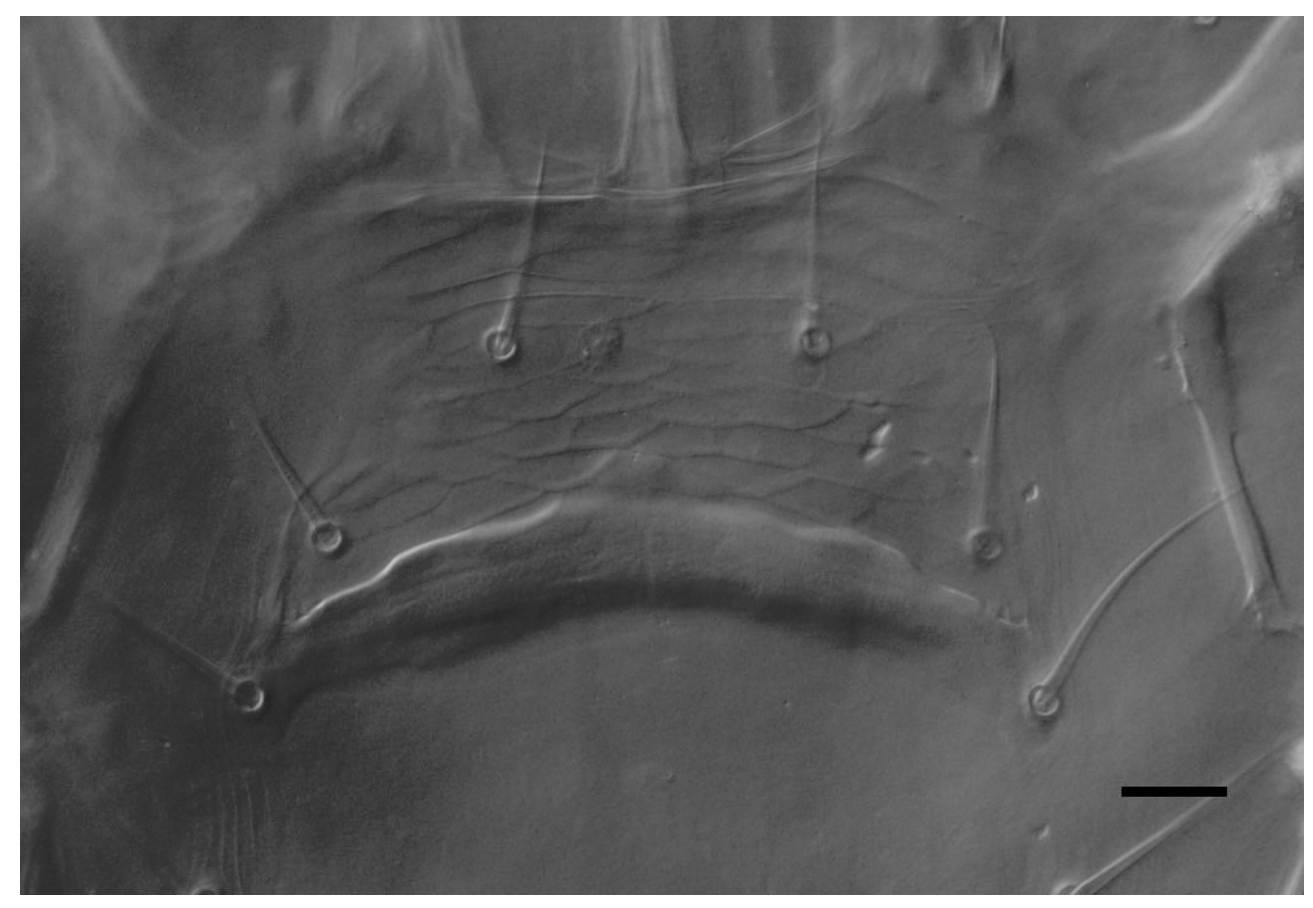

Figure 3 Female of Steatonyssus afer. Sternal shield (scale bar $20 \mu \mathrm{m}$ ).

Gnathosoma: deutosternum with 7 teeth arranged in single file (Fig. 5).

Legs: coxae II bears pronounced anterodorsal spur; in a single specimen from Mudorib River its tip divided into four denticles. Chaetotaxy of the legs typical for the genus (Fig. 6).

Material examined - One female sampled from C. seabrae in Okongwe $\left(18^{\circ} 59^{\prime} \mathrm{S}\right.$ $13^{\circ} 9^{\prime} \mathrm{E}$ ) (4 I 2017; coll. T. Laverty) and four females from C. seabrae close to the Mudorib River $\left(19^{\circ} 19^{\prime} \mathrm{S} 13^{\circ} 14^{\prime} \mathrm{E}\right)$ (6 XII 2016; coll. T. Laverty) (Kunene Region, Namibia).

Distribution - Angola (type locality) (Radovsky, Yunker, 1963), Sierra Leone (Till, Evans, 1964), Afghanistan (Dusbábek, 1970), Namibia (our data, first record).

Hosts - Neoromicia nana (as Pipistrellus nanus - Radovsky, Yunker, 1963), Neoromicia

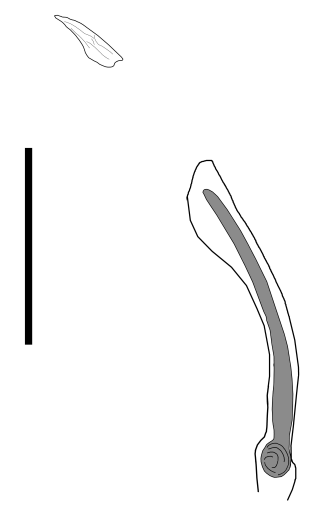

Figure 4 Female of Steatonyssus afer. Peritreme and peritremal shields (scale bar $100 \mu \mathrm{m}$ ). 


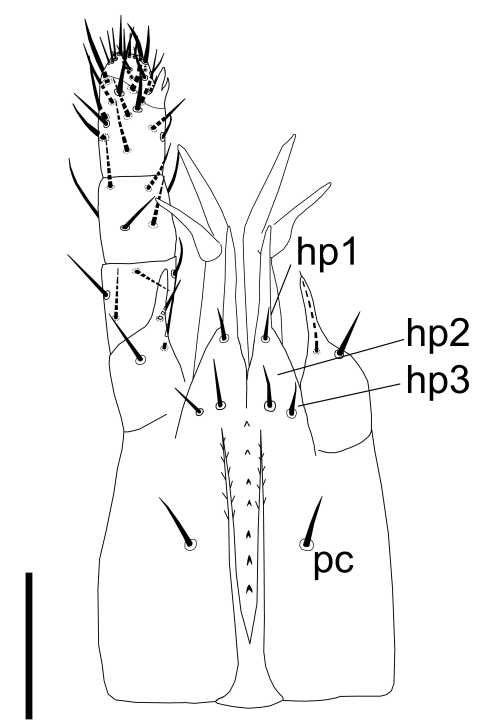

Figure 5 Female of Steatonyssus afer. Gnathosoma (scale bar $20 \mu \mathrm{m}$ ).

tenuipinnis (Chiroptera: Vespertilionidae) (as Eptesicus tenuipinnis - Radovsky, Yunker, 1963), Nycteris macrotis (Chiroptera: Nycteridae) (Radovsky, Yunker, 1963), Eptesicus serotinus (Chiroptera: Vespertilionidae) (Dusbábek, 1970), Rhinopoma sp. (Chiroptera: Rhinopomatidae) (Dusbábek, 1970), Cistugo seabrae (Chiroptera: Cistugidae) (our data, first record).

Remarks - We note that there is a fairly large variation in size among the mites recorded so far (in Namibia in this study and in different regions in the literature; Table 1). Since we were only able to examine five specimens from Namibia (from five bats in two distant localities) and could not standardize our measurements by performing them in parallel on the types, we cannot conclude about possible crypticism within the species $S$. afer. However, we suggest that
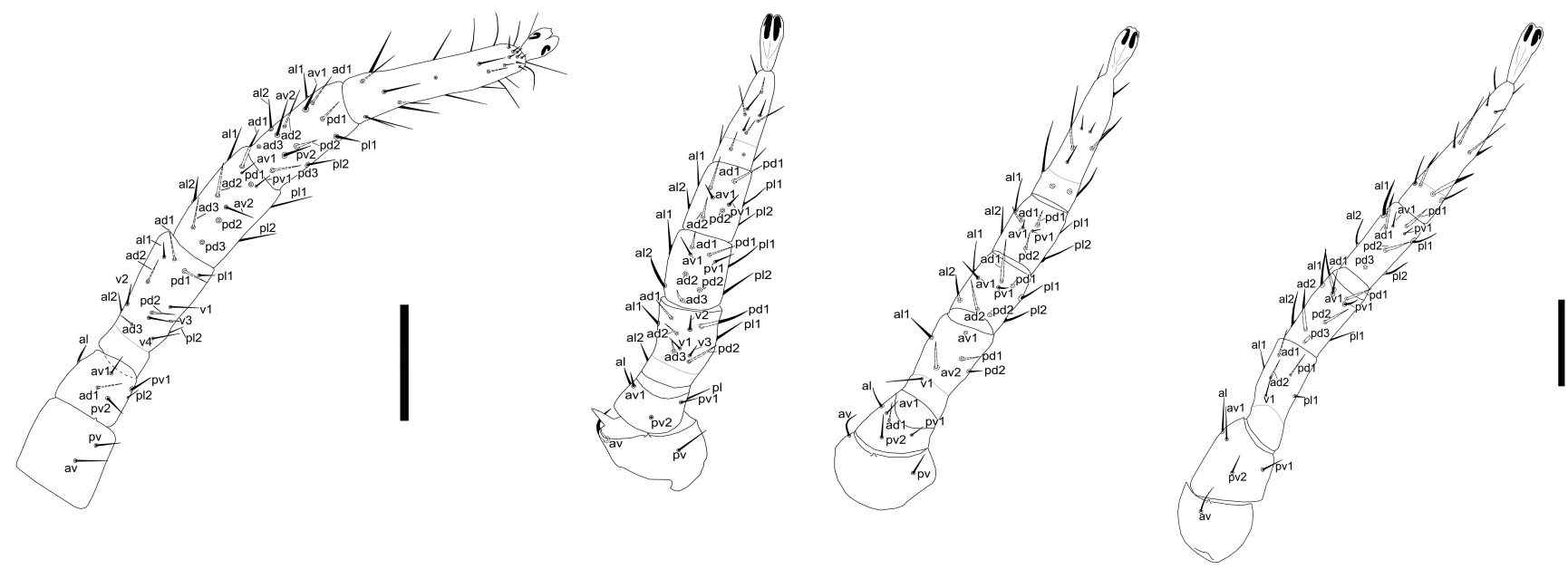

Figure 6 Female of Steatonyssus afer. Legs (scale bar $100 \mu \mathrm{m})$. 
Table 1 Comparison of metric data of body parts between Steatonyssus afer adult female from Namibia and those described in Angola. All measurements are given in micrometers $(\mu \mathrm{m})$.

\begin{tabular}{|c|c|c|c|}
\hline Body part & $\begin{array}{c}\text { Steatonyssus afer } \\
\text { Angola } \\
\text { (Radovsky, Yunker, 1963; } \\
\text { Till, Evans, 1964) }\end{array}$ & $\begin{array}{c}\text { Steatonyssus afer } \\
\text { Namibia } \\
\text { (this paper) }\end{array}$ & $\begin{array}{c}\text { Steatonyssus roeri } \\
\text { Namibia } \\
\text { (Coffee, 1973) }\end{array}$ \\
\hline Idiosoma, length & 849 & $\approx 1000$ & - \\
\hline Idiosoma, width & 503 & $\approx 700$ & - \\
\hline Podonotal shield, length & 276 & $297.0 \pm 6.6(289-304)$ & 288 \\
\hline Podonotal shield, width & - & $250.8 \pm 6.9(242-258)$ & 278 \\
\hline$j 2$ & - & $28.5 \pm 2.7(26-32)$ & $24-26$ \\
\hline$z 2-3, s 3-4$ & $67-76$ & $74.9 \pm 3.2(71-80)$ & - \\
\hline Opistonotal shield, length & $308-338$ & $357.2 \pm 7.3(347-367)$ & $365-403$ \\
\hline Opistonotal shield, width & $180-195$ & $204.4 \pm 9.4(194-213)$ & 202 \\
\hline$J 1-3$ & $64-71$ & $59.5 \pm 5.5(52-66)$ & $40-47$ \\
\hline$S 5$ & - & $10.3 \pm 0.8$ & 14 \\
\hline Sternal shield, length & 57 & $57.2 \pm 3.8(51-60)$ & $54-59$ \\
\hline Sternal shield, width & - & $155.8 \pm 2.7(153-160)$ & $127-137$ \\
\hline St 1 & $39-43$ & 39 & - \\
\hline St 3 & $67-72$ & 71,72 & - \\
\hline St $1-S t 1$ & 47 & $61 \pm 2.5(59-64)$ & $61-64$ \\
\hline Epigynial shield, length & - & $313.8 \pm 15.0(296-329)$ & - \\
\hline Epigynial shield, width & - & $111.8 \pm 5.4(106-119)$ & - \\
\hline Anal shield, length & $150-165$ & $186.8 \pm 5.2(181-194)$ & $125-137$ \\
\hline Anal shield, width & $74-82$ & $90.8 \pm 2.2(88-93)$ & $85-96$ \\
\hline Dorsal opistosomal setae, length & - & $74.5 \pm 2.6(71-78)$ & - \\
\hline Ventral opistosomal setae, length & - & $50.5 \pm 8.0(39-60)$ & - \\
\hline Tibia I & 87 & 94,101 & - \\
\hline Tarsal I & $157-160$ & 177,182 & - \\
\hline Tibia IV & 80 & 99,103 & - \\
\hline Tarsal IV & $168-180$ & 208 & - \\
\hline
\end{tabular}

it would be useful to explore the genetic structure of this taxon by morphological comparisons on a larger and more representative sample and, if possible, by adding a molecular analysis to the morphological analysis.

The individuals present the first record of $S$. afer for Namibia and the southernmost locality for the species to date. Also, C. seabrae is recorded as another host of the parasite.

Given the poor knowledge of genus Steatonyssus in Africa, there is a need for further research on Steatonyssus species throughout Africa to establish complete host lists and geographical ranges of these ectoparasites.

\section{Acknowledgments}

This work was supported by a National Science Foundation Graduate Research Fellowship to TML and by the Tomsk State University Competitiveness Improvement Program to MVO. 
We are grateful to Dr. B. Halliday for his valuable comments and to the anonymous reviewers, whose advices made our manuscript substantially better.

\section{Ethical approval}

All applicable institutional, national and international guidelines for the care and use of animals were followed. Fieldwork was conducted with in accordance with the guidelines of Colorado State University's Institutional Animal Care and Use Committee (Protocol \#15-6140A) and the Ministry of Environment and Tourism, Republic of Namibia (research/collecting permits $\# 2122 / 2016$ and \#2225/16).

\section{References}

Coffee G. M. 1973. Two new species of Steatonyssus from the Ethiopian Region Acarina Mesostigmata. Zeitschrift fuer Angewandte Zoologie.60 (1):21-29.

Dusbábek F. 1970. Mite parasites (Acarina) of bats from Afghanistan. Folia Parasitolog. 17:61-76. Jacobson P., Jacobson K. 2013. Hydrologic controls of physical and ecological processes in Namib Desert ephemeral rivers: implications for conservation and management. J. Arid. Environ., 93:80-93. doi:10.1016/j.jaridenv.2012.01.010

Monadjem A., Taylor P.J., Cotterill F.P.D., Schoeman M.C. 2010. Bats of Southern and Central Africa: A biogeographic and taxonomic synthesis. Wits University Press: Publisher. pp. 596.

Radovsky F. 1967. The Macronyssidae and Laelapidae (Acarina: Mesotigmata) parasitic on bats. Barkeley, University of California: Publisher. pp. 288.

Radovsky F. 2010. Revision of Genera of the parasitic mite family Macronyssidae (Mesostigmata: Dermanyssoidea) of the world. Indira Publishing House: Publisher. pp. 170

Radovsky F. J., Yunker C. E. 1963. Four New Species of Steatonyssus from Africa (Acarina: Dermanyssidae). The Journal of Parasitology, 49 (2): 334-339. doi:10.2307/3276009

Till M. W., Evans O. G. 1964: The genus Steatonyssus Kolenati (Acari: Mesostigmata). Bulletin of the British Museum (Natural History), Zoology Series. 11: 511-582. doi:10.5962/bhl.part.4724

Whitaker J. O. Jr. 1988. Collecting and preserving ectoparasites for ecological study. Ecological and Behavioral Methods for the Study of Bats. Washington: Smithsonian Inst. Press Publisher: 459-474. 